\title{
Structural changes of the homologues as a possible cause of abnormal disjunction in female mice heterozygous for Robertsonian translocations
}

\author{
A.O. RUVINSKY, S.I. AGULNIK, A.I. AGULNIK and D.K. BELYAEV \\ Institute of Cytology and Genetics, Academy of Sciences of the USSR, \\ Siberian Division, Novosibirsk-90, USSR
}

\begin{abstract}
Summary
Mutations $T, F u$ and $t^{6}$-haplotype on chromosome 17 cause preferential transmission of the acrocentric homologues in the progeny of female mice heterozygotes for Robertsonian translocations $(R b)$. The present results demonstrate that the influence of these mutations upon segregation is restricted to the Robertsonian translocations involving chromosome 17. Substitution of parts of chromosome 17 distal or proximal to the $T$ locus did not alter the effect of this chromosome on the transmission rate of the homologue. The effects of these mutations, whether cis or trans with $R b$, on the transmission were the same. It was established that $R b 13 L u b t^{\omega L u b \cdot I}+1++t f$ females reveal significant segregation distortion. However, in the progeny of $R b 13 L u b t^{\text {wLub-1}} /+t^{b}$ females, chromosome segregation did not differ from that theoretically expected. $R b 7 / T 43 H$ mothers transmitted the chromosome with the reciprocal translocation $\mathrm{T} 43 \mathrm{H}$ to $70.9 \%$ of their progeny. Thus data were obtained supporting the idea that structural changes of the chromosomes caused by mutations affect the segregation of the homologues in $R b$ heterozygous females.
\end{abstract}

Key words : mice, Robertsonian translocation, chromosome segregation.

\begin{abstract}
Résumé
Modifications de la structure des chromosomes homologues : une cause possible de la disjonction anormale chez les souris femelles hétérozygotes pour des translocations robertsoniennes
\end{abstract}

La présence des mutations $T, F u$ ou du haplotype $t^{6}$ sur le chromosome 17 entraine une transmission préférentielle des chromosomes homologues acrocentriques aux produits de souris femelles hétérozygotes pour des translocations robertsoniennes $(R b)$. Les résultats présentés dans cet article montrent que l'influence de ces mutations sur la ségrégation est limitée aux translocations robertsoniennes impliquant le chromosome 17. La substitution de fragments du chromosome 17 distaux ou proximaux par rapport au locus $T$ n'altère pas l'effet de ce chromosome sur le taux de transmission du chromosome homologue. Ces mutations ont le même effet sur la transmission, qu'elles soient en position cis ou trans par rapport à la translocation robertsonienne $(R b)$. Il a été établi que les femelles $R b 13 L u b t^{w L u b-l}+1++t f$ présentent une distorsion de ségrégation significative. Cependant, chez les produits de femelles $R b 13 L u b t^{\omega L u b-l} /+t^{6}$, la ségrégation des chromosomes ne diffère pas de celle théoriquement attendue. Les mères $R b / T 43 H$ transmettent le chromosome portant la translocation réciproque $T 43 H$ à $70,9 \%$ de leurs produits. Ainsi, les résultats obtenus 
sont en faveur de l'hypothèse selon laquelke des modifications de la structure chromosomique causées par des mutations affectent la ségrégation des chromosomes homologues chez les femelles portant une translocation robertsonienne à l'état hétérozygote.

Mots clés : souris, translocation robertsonienne, ségrégation chromosomique.

\section{Introduction}

The influence of mutations on chromosome 17 upon the segregation of the metacentric and acrocentric homologues in the progeny of female mice heterozygous for Robertsonian translocations $R b(8.17) 1 \mathrm{lem}$ and $R b(16.17) \mathrm{Bnr}$ was studied previously (RUvinsky et al., 1987). Genetic analysis indicated that portion of non- $R b$ (normal karyotype) progeny from mothers heterozygous for mutations $t f, q k, t^{12}$ was weakly different from the $50 \%$ Mendelian expected level (55-57\%). Introduction of mutations $T, F u^{\mathrm{Ki}}, F u, t^{6}$ into the female genotype caused a more severe segregation distortion and an increase in the portion of progeny with normal karyotype (63-67\%). Based on results of the cytogenetic analysis of blastocysts and oocytes at M II of meiosis, it was concluded that the preferential distribution of the metacentric to the polar body during the first meiotic division had a bearing on the observed segregation distortion. To our knowledge, the mechanism of this unequal transmission of the homologues has not been, so far, considered. The relevance of events occurring at the prophase of meiosis to this segregation distortion was another question of no less importance. The problem is, how does the segregation distortion arise. There is probably more than one answer, but the present paper is an attempt to find one.

\section{Materials and methods}

The mutations on chromosome 17 and the Robertsonian translocations $R b(8.17) 11$ lem $(R b 1), R b(16.17) 7 B n r(R b 7)$ it carries were described in the preceding paper (Ruvinski et al., 1987). The mouse stocks used were one outbred homozygous for $R b 1$ and $R b(2.6) 4 I e m(R b 4)$ (BARANOv, 1981) and another bearing $R b(3.5) 1 I c$ $g(R b 1 I c g)$ (AgULNiK et al., 1983). The translocation $R b(4.17) 13 L u b(R b 13 L u b)$ containning the $t^{\mathrm{wLub}-1}$ haplotype on chromosome 17 was derived from the $R b 13 L u b t^{\mathrm{wLub}-1} / \mathrm{Ttf}$ stock. $R b 13 L u b t^{\mathrm{wLub}-1} /+t^{6}$ females were produced by intercrossing $R b 13 L u b t^{\mathrm{wLub}-1} / T t f$ and $t^{6} / T t f$ mice and collecting the normal tailed progeny ; Rb13Lubt $t^{\mathrm{wLub}-1}+1+t f f$ females were obtained from $ᄋ t f / t f \times \sigma^{\top} R b 13 L u b t^{\mathrm{wLub}-1} /+T t f$ crosses. Mutation Sd (Denforth's short tail) was derived from the $S d R a /++$ stock. Mice carrying the reciprocal translocation $T(16 ; 17) 43 H$ with one break located in the medial part of chromosome 17 , and the second in the centromeric heterochromatin of chromosome 16 were also used. Carriers of recombinant chromosomes $T+$ and (R.C.) $T t f$ with substitutions distal and proximal to the $T$ locus in the original $T t f$ chromosome were obtained from the $R b 7++1+T t f$ 우 $\times++t f /++$ tf $\sigma^{\prime \prime} \sigma^{\prime \prime}$ and $R b 7 T t f /++t f ㅇ \times++t f /++t f \sigma^{7} \sigma^{\prime \prime}$ crosses. Mice carrying mutations $T f, T, F u$ in cis with $R b 7$ were obtained from the $R b 7+1+t f q Q \times+t f /$ tf $\sigma^{\prime \prime} \sigma^{\prime \prime}, R b 7++/+F u+q Q \times++t f /++t f \sigma^{\prime \prime} \sigma^{\prime \prime}$ and $R b 7++/+T t f q$ 우 $\times++t f /++t f$ $\sigma^{\prime \prime} \sigma^{\prime \prime}$ crosses. To identify carriers of the recombinant chromosomes, preparations of 
bone marrow cells obtained by biopsy were studied cytogenetically. The G-banding method was applied for chromosome identification in the progeny of females carrying either of the two Robertsonian translocations or T43H. All offspring obtained have been karyotyped.

\section{Results}

Certain mutations on chromosome 17 have the property of lowering the transmission rate of the metacentric involving this chromosome and raising that of the corresponding acrocentrics in the progeny from heterozygous females. The question was whether these mutations on chromosome 17 may influence transmission of the metacentrics and the corresponding acrocentrics involving chromosomes other than chromosome 17. In females diheterozygous for $R b 1$ and $R b 4$, the $T$ mutation has no effect on the transmission of $R b 4$, while it significantly affects that of $R b 1$ (table 1). What is also noteworthy, is that mutation $S d$ (chromosome 2) has no significant influence on the transmission of $R b 4$ and $R b 1$ (Cross 1). Thus the data demonstrate that the influence of mutations on chromosome 17 is restricted to Robertsonian translocations involving precisely this chromosome. Support was also derived from the data of table 2 . There

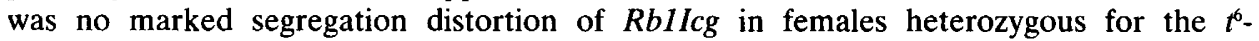
haplotype or the $T$ mutation.

TABLE 1

Chromosome segregation in the progeny of females diheterozygous for $\mathrm{Rb}(8.17) 1 \mathrm{Iem}$ and $\mathrm{Rb}(2.6) 4 \mathrm{Iem}$ mated to $\mathrm{tf} / \mathrm{tf}$ males

\begin{tabular}{|c|c|c|c|c|c|c|c|c|}
\hline \multirow[b]{2}{*}{$\mathbf{N}^{\circ}$} & \multirow[b]{2}{*}{ Female genotype } & \multirow{2}{*}{$\begin{array}{c}\text { Total } \\
\text { offspring }\end{array}$} & \multicolumn{4}{|c|}{ Progeny genotype } & \multirow{2}{*}{$\begin{array}{c}\% \\
\text { Non- } R b l\end{array}$} & \multirow{2}{*}{$\begin{array}{c}\% \\
\text { Non- } R b 4\end{array}$} \\
\hline & & & $\begin{array}{c}+/+ \\
R b 4 /+\end{array}$ & $\begin{array}{l}+1+ \\
+1+\end{array}$ & $\begin{array}{l}R b 1 /+, \\
R b 4 /+\end{array}$ & $\begin{array}{l}R b 1 /+ \\
+/+\end{array}$ & & \\
\hline 1 & $R b 1 /+, R b 4+1+S d \ldots$ & 97 & 30 & 17 & 22 & 28 & 48.5 & 46.4 \\
\hline \multirow[t]{2}{*}{2} & $R b l+l+t f, R b 4 I+\ldots$ & 111 & 24 & 33 & 25 & 29 & 51.4 & 55.9 \\
\hline & $1+2$ (Control) $\ldots$ & 208 & 54 & 50 & 47 & 57 & 50.0 & 51.4 \\
\hline 3 & $R b 1++/+T t f, R b 4 /+$ & 227 & 61 & 81 & 39 & 46 & $62.6^{*}$ & 55.9 \\
\hline
\end{tabular}

* The difference is significant, $P<0.01(F \varphi=7.0)$. The transmission rate of $50.0 \%$ is taken as the control value.

TABLE 2

Chromosome segregation obtained in the presence of mutations $\mathrm{t}^{6}$ or $\mathrm{T}$ in the progeny of females heterozygous for $\mathrm{Rb}(3.5) 1 \mathrm{Icg}$ mated to $\mathrm{tf} / \mathrm{tf}$ males

\begin{tabular}{|c|c|c|c|c|c|}
\hline \multirow{2}{*}{ Female genotype } & \multirow{2}{*}{$\begin{array}{c}\text { Total } \\
\text { offspring }\end{array}$} & \multicolumn{3}{|c|}{ Progeny genotype } & \multirow{2}{*}{$x^{2}$} \\
\hline & & $\mathbf{R b}$ & Non- $\mathrm{Rb}$ & $\%$ Non-Rb & \\
\hline$t^{6} l+, R b I I c g l+$ & 114 & 51 & 63 & 55.3 & 1.4 \\
\hline$T t f l++, R b 1 \mid c g l+\ldots \ldots$ & 92 & 42 & 50 & 54.3 & 0.7 \\
\hline
\end{tabular}


This suggests that the effect of certain mutations on chromosome 17 upon the transmission of $R b$ translocations presumably is not a consequence of the influence of putative products of these mutations on transmission, but is rather due to meiotic interaction of the homologues.

The point to settle is whether this interaction effect upon segregation is the direct consequence of the mutations $\left(T, F u, F u^{\mathrm{Ki}}, t^{6}\right)$ previously studied (RuviNsKI et al., 1987) or the result of an influence of the genotypic milieu. It is known that $R b 7$ causes a significant segregation distortion in progeny of heterozygous females even in the absence of the studied mutations of chromosome 17 (GropP \& WINKING, 1981). This distortion is enhanced when the acrocentric chromosome with $T$ mutation is present. The data of table 3 indicate that substitution of the distal (Cross 6) or proximal (Cross 7) regions of the $T$-bearing chromosome does not alter significantly the proportions of $R b$ progeny and progeny with the standard karyotype (Cross 5). A comparison of Cross 1 and Crosses 5 and 6 shows significant differences in the proportion of non$R b$ progeny. The difference between Cross 7 and Cross 1 is of the same level, but not significant, due to restricted sample size. This gave reason for assuming that precisely mutation $\mathrm{T}$ is responsible for the disturbed segregation, but not the set of genes or constitution of chromosome 17. To verify this assumption, we compared the effect of $T$ and $F u$ upon the transmission of $R b 7$ when placed in trans or cis with it (table 3 ). The dominant genes $F u$ (Crosses 3, 4) and $T$ (Crosses 5, 8) caused a gross segregation distortion, whether the configuration was cis or trans.

\section{TABLE 3}

Segregation ratio of homologues in the progeny of $\mathrm{Rb}(16.17) 7 \mathrm{Bnr}$ heterozygous females bearing a mutation on chromosome 17 and mated to $\mathrm{tf} / \mathrm{tf}$ males

\begin{tabular}{|c|c|c|c|c|c|}
\hline \multirow{2}{*}{$\mathrm{N}^{\mathrm{o}}$} & \multirow{2}{*}{ Female genotype } & \multirow{2}{*}{$\begin{array}{c}\text { Total } \\
\text { offspring }\end{array}$} & \multicolumn{3}{|c|}{ Progeny genotype } \\
\hline & & & $\mathrm{Rb}$ & Non- $R b$ & $\%$ Non- $R b$ \\
\hline 1 & $R b 7+1+t f \ldots \ldots \ldots \ldots$ & 350 & 149 & 201 & 57.4 \\
\hline 2 & $R b 7 t f l+t f \ldots \ldots \ldots \ldots$ & 58 & 25 & 33 & 57.0 \\
\hline 3 & $R b 7+1+F u \ldots \ldots \ldots$ & 432 & 149 & 283 & $65.5^{*}$ \\
\hline 4 & $R b 7 F u+l++t f$ & 116 & 34 & 82 & $70.9 *$ \\
\hline 5 & $R b 7++1+T t f$ & 314 & 110 & 204 & $65.0^{*}$ \\
\hline 6 & $R b 7+/+T \ldots \ldots$ & 186 & 60 & 126 & $67.7^{*}$ \\
\hline 7 & $R b 7++/($ R.C. $) T t f$ & 108 & 39 & 69 & 63.9 \\
\hline 8 & $R b 7 T t f l++t f \ldots \ldots \ldots \ldots$ & 216 & 62 & 154 & $71.3 *$ \\
\hline
\end{tabular}

* Significantly differ from total value of crosses 1 and $2(P<0.05)$, based on $F \varphi$ - criteria.

An additional experiment was run to determine whether $t$-haplotype also affects transmission of $R b$ translocations, being in cis-position. The data on the analysis of progeny of females heterozygous for translocation $R b 13 \mathrm{Lub}$ are presented in table 4 . In the case of heterozygosity for the translocation and $t$-haplotype there is a sharp distortion in the transmission of homologues of offspring $(68.3 \%$ non $R b)$. The absence of a $R b 13 L u b$ translocation without a $t$-haplotype in our collection, and difficulties in obtaining such a chromosome prevented us from studying its segregation pattern in $R b 13 \mathrm{Lub} /+$ females. Nevertheless we produced some crosses to study the mode of 
tranmission in females heterozygous for $R b 13 L u b$ and carrying the $t^{\mathrm{wLubl}}$ and $t^{6}$ haplotypes. It was observed that segregation ratio did not significantly differ from the theoretically expected 1:1 value (table 4). These data indicate that the presence of $t$ haplotypes on both homologues of chromosome 17 , restores the normal segregation in females heterozygous for the $R b$ translocation.

TABLE 4

Chromosome segregation in the progeny of females heterozygous for $\mathrm{Rb}(4.17) 13 \mathrm{Lub}$ mated to $\mathrm{tf} / \mathrm{tf}$ males

\begin{tabular}{|c|c|c|c|c|}
\hline \multirow{2}{*}{ Female genotype } & \multirow{2}{*}{$\begin{array}{c}\text { Total } \\
\text { offspring }\end{array}$} & \multicolumn{3}{|c|}{ Progeny genotype } \\
\hline & & $R b$ & Non- $R b$ & $\%$ Non- $R b$ \\
\hline$R b 13 L u b t^{w L u b-1}+1++t f$ & 189 & 60 & 129 & $68.3^{*}$ \\
\hline$R b 13 L u b t^{w L u b \cdot l} /+t^{b} \ldots$ & 103 & 46 & 57 & 55.3 \\
\hline
\end{tabular}

${ }^{*} P<0.05(F \varphi=4.8)$

Results from these three series of experiments show that segregation distortion occurs for three different $R b$ translocations all involving chromosome 17.

The present (table 1-4) and previous results (Ruvinsky et al., 1987) considered as a whole, incline us to the view that structural changes in chromosomes bearing certain mutant genes cause meiotic disorder.

TABLE 5

Chromosome segregation in the progeny of females heterozygous for $\mathrm{T}(16 ; 17) 43 \mathrm{H}$

\begin{tabular}{|c|c|c|c|c|c|c|}
\hline \multirow{2}{*}{$\mathrm{N}^{\mathrm{o}}$} & \multicolumn{2}{|c|}{ Genotype } & \multirow{2}{*}{$\begin{array}{c}\text { Total } \\
\text { offspring }\end{array}$} & \multicolumn{3}{|c|}{ Progeny genotype for $T 43 \mathrm{H}$} \\
\hline & Female & Male & & $T 43$ & + & $\% T 43$ \\
\hline 1 & $T t f+/++T 43 H$ & $R b 7 / R b 7$ & 52 & 27 & 25 & 51.9 \\
\hline 2 & $F u(+)+/++T 43 H^{+}$ & $R b 7 / R b 7$ & 190 & 106 & 84 & 55.8 \\
\hline 3 & $R b 7 / T 43 H$ & $t f / t f$ & 117 & 83 & 34 & $70.9^{*}$ \\
\hline
\end{tabular}

$\dagger$ Mice with genotypes $F u+/+T 43 H$ and $F u t f+/++T 43 H$.

* The difference is significant, $P<0.01(F \varphi=7.0)$. The transmission rate of $57.4 \%$ calculated for $R b 7+l+t f$ females is taken as the control value.

Decisive evidence for this view was provided by the segregation data for reciprocal translocation $T 43 H$, touching the structure of the proximal region of chromosome 17 (table 5). In female $T 43 H$ heterozygotes (crosses 1 and 2), there was no segregation distortion of the homologues in the progeny in spite of the presence of $T$ and $F u$ mutations. In contrast, $70.9 \%$ of the progeny of $R b 7 / T 43 H$ received $T 43 H$ from their mothers. This segregation distortion seems to be specific to interaction between the $R b 7$ and $T 43 H$ translocations. Thus there is good agreement between the data for the effects of $T 43 \mathrm{H}$, and some mutations of chromosome 17 studied here and previously. 


\section{Discussion}

Heterozygosity for certain $R b$ translocations in female mice results in deviation from Mendelian segregation in favour of the non- $R b$ progeny (Gropp \& WINKING, 1981). We demonstrated that the presence of dominant mutations, $T, F u, F u^{\mathrm{Ki}}$ and $t^{b}$, $t^{\mathrm{wLubl}}$ haplotypes increases the preferential transmission of the acrocentric homologue of chromosome 17. It was shown that the phenomenon observed was based on the preferential movement of the metacentric chromosome to the first polar body during female meiosis. What may, conceivably, be the cytogenetic mechanism of the nonfortuitous access of $R b 7, R b l$ and may be other translocations to the first polar body in females bearing studied mutations and $t$-haplotypes ?

Synapsis in the precentromeric region appears to be fraught with potential difficulties for heterozygotes of some Robertsonian translocations. One of the reasons may be that the mouse has true (in the strict sense of the term) acrocentric chromosomes. They have a short arm too (John \& Freeman, 1975 ; Johannisson \& Winking, 1979). The total length of the two acrocentrics exceeds that of their corresponding metacentric chromosome (DEMiN et al., 1984). However, synaptic correction (Moses, 1977) makes it possible to overcome this potential impediment and, as a result, pairing and subsequent segregation proceed smoothly. Robertsonian translocations $R b(1.3) 1 B n r, R b(6.13) 3 R m a$, $R b(4.15) 4 R m a, R b(16.17) 7 B n r$ and, perhaps, others, are exceptions in this respect. Equal transmission of the homologues is significantly distorted in females heterozygous fot these translocations (Gropp \& WINKING, 1981).

A structural mutation introduced into one of the pairing chromosome (whether the metacentric or the acrocentric) can obstruct the correction of the potential hindrance to synapsis. It was shown that recombination between centromere 17 and $\mathrm{T43H}$ break was reduced almost to zero in mice $R b 7+l+T 43 H$ (ForeJT et al., 1980). Our observations presented here demonstrate a strong segregation distortion in the progeny of females with the same genotype in favour of the acrocentric chromosomes bearing the $T 43 \mathrm{H}$ translocation. Thus, it may be supposed that the structural mutation $T 43 H$ changes the normal course of synapsis, recombination and segregation. It is also known that pairing of the desynaptic type is disturbed in $R b 7+/+t^{w 5}$ males (Tres \& ERICKson, 1982). The same may occur in females. Disturbed pairing takes place in the prophase of meiosis. Two unpaired centromeres of the acrocentrics may be formed in the trivalent. We cannot describe the exact pattern of meiotic behaviour of the trivalent now. But it seems probable that these centromeres come into contact with the spindle threads radiating from the centre of the oocyte, and this contact orientates movement of the acrocentric at anaphase I. If so, one may argue that the first polar body is, by logical necessity, the most probable target for the metacentric chromosome.

It is interesting to note that reconstruction of the pairing chromosomes homology as was done in females $R b 13 L u b t^{\mathrm{wLub-1} /} /+t^{6}$, led to normal segregation. This, to our mind, clearly verifies the importance of structural changes of homologues for the genesis of meiotic disturbances.

It is pertinent to recall that the probability for the $\mathrm{X}$ chromosome to remain in the oocytes of $\mathrm{X} 0$ females is $70 \%$, and for it to enter the first polar body is $30 \%$ (KaufMan, 1972 ; LuthardT, 1976). Whichever the case may be, the cytogenetic 
scenario is the same. This lends more credibility to the idea that chromosome structure can result in distorted segregation of homologues in female $R b$ heterozygotes.

The present data make it possible that $T$ and $F u$ are not the point mutations previously thought (DUNN \& CASPARI, 1945 ; GREEN, 1981) ; they appear rather to be related to structural changes along big stretches of the chromosome. This is in compliance with the known structure of the $T$-alleles, some of which, such as $T^{\text {hp }}, T^{\text {Orl }}$, $T^{\text {tor-for, }}$ are long deletions extending over the precentromeric region of chromosome 17 . Investigation of the molecular organization of the $t$-complex pursued now may provide a crucial test for this assumption. If, indeed, extensive changes of chromosome structure underlie the effects of the studied mutations upon the segregation of the homologues, it would be possible to express changes of chromosome structure as measurable units of segregation distortion.

Received March 20, 1987. Accepted November 16, 1987.

\section{Acknowledgements}

We are very grateful to Dr. V.S. Baranov (Leningrad, USSR), Dr. J. ForeJt (Prague, Czechoslovakia), Dr. J. KLEIN (Tübingen, FRG) for the gifts of mouse stocks and Miss A.N. FADEEva for translation from Russian into English.

\section{References}

Agulnik S.I., Agulnik A.I., Ruvinsky A.O., 1983. Private communication. Mouse News Letter, $69,41$.

BaRAnov V.S., 1981. Rb(2.6)4lem - a new marker Robertsonian translocation in laboratory mouse Mus musculus (in Russian). Tsitologia, 23, 1362-1367.

Demin Yu.S., Safronova L.D., Cherejanova L.V., Safronov V.A., 1984. Investigation of synaptonemal complexes of mammals. 1. The nature and mechanism of formation of chromosomes centric fusion (Robertsonian translocations) (in Russian). Genetika, 20, 1499-1506.

Dunn L.C., Casparl E., 1945. A cause of neighboring loci with similar effects. Genetics, 30, 543568.

Forejt J., Capkova J., Gregorova S., 1980. T(16;17)43H translocation as a tool in analysis of the proximal part of chromosome 17 (including $T-t$ gene complex) of the mouse. Genet. Res., 35, 165-177.

Green M.C., 1981. Catalog of mutant genes and polymorphic loci. In : Green M.C. (ed.), Genetic variants and strains of the laboratory mouse, 8-278, Gustav Fischer Verlag, Stuttgart.

Gropp A., WINKING H., 1981. Robertsonian translocation : cytology, meiosis, segregation patterns and biological consequences of heterozygosity. Symp. Zool. Soc., Lond., 47, 141-181.

Johannisson R., Winking H., 1979. Synaptonemal complex of multivalents in mouse spermatocytes. Europ. J. Cell Biol., 20, 122.

John B., Freeman M., 1975. Causes and consequences of Robertsonian exchange. Chromosoma, 52, $123-136$. 
Kaufman M.N., 1972. Non-random segregation during mammalian oogenesis. Nature, 238, 465466.

LUTHARDT F.W., 1976. Cytogenetic analysis of oocytes and early preimplantation embryos from XO mice. Dev. Biol., 54, 73-81.

Moses M.J., 1977. Microspreading and synaptonemal complex in cytogenetic studies. Chromosomes Today, 6, 71-82.

Ruvinsky A.O., Agulnik S.I., Agulnik A.I., Belyaev D.K., 1987. The influence of mutations on chromosome 17 upon the segregation of the homologues in female mice heterozygous for Robertsonian translocations. Genet. Res., 50, 235-237.

Tres L.L., Erickson R.P., 1982. Electron microscopy of t-allele synaptonemal complexes discloses no inversion. Nature, 299, 752-754. 